\section{HUGO physical mapping}

SIR-HUGO, the international Human Genome organization, has adopted as one of its main objectives the coordination of physical mapping efforts on individual chromosomes. It is our desire to sponsor, on a chromosome-by-chromosome basis, committees, workshops and scientific meetings aimed at facilitating exchanges of data, samples and materials and optimizing the integration of individual laboratory efforts. HUGO will also help to coordinate these evolving physical mapping efforts with the existing chromosome committees of the Human Gene Mapping Workshops. HUGO staff will be able to provide guidelines for committees, workshops and meetings on the basis of past experience. It is ready to aid in the planning and organization of these meetings, including assistance in the preparation and submission of applications for funds to support them. In addition, HUGO has some funds of its own which may be available to supplement support received from other sources.

Individuals currently involved, or interested in participating in organizing efforts on particular chromosomes should contact any one of the three regional HUGO offices listed below*. It is expected that these three offices will share the overall administrative burden for physical mapping, with particular offices playing a leading role for individual chromosomes as appropriate.

Several guiding principles will determine HUGO's role in selecting particular chromosome activities for support and encouragement. HUGO is committed to the principle of free exchange of materials and information. Only one organized group for each chromosome can receive official HUGO sponsorship. However, this group need not have a single lead organization or individual, provided that there is a suitable plan for collective management representing the bulk of the researchers interested in that particular chromosome. HUGO will maintain a summary of existing coordination activities on each chromosome.

HUGO will act as an information exchange centre for communication among the individual chromosome efforts. It will provide working examples of effectively organized data sharing, sample sharing, workshops and committee structure as these emerge. At present (during the current period of rapid changes in technologies and strategies), there is no consensus on how physical mapping activity should be organized or implemented. Coordination of these efforts, through HUGO, after an initial period of experimentation should enable a better definition of global strategies and procedures to be developed over the next few years. CHARLES R. CANTOR

Human Genome Center,

Lawrence Berkeley Laboratory,

1 Cyclotron Road,

Berkeley, California 94720, USA

* HUgO America, Ms Diane Hinton, Howard Hughes Medical Institute 6701 Rockledge Drive, Bethesda MD 20817 USA (Tel: (301) 571-0282, Fax: (301) 571-0573). HUGO Europe, Dr Bronwen Loder, Imperial Cancer Research Fund, PO Box 123, Lincoln's Inn Fields, London WC2A 3PX, UK (Tel: 4471-269-3610, Fax: 44-71-831-6265). HUGO Asia, Dr Kenichi Matsubara, institute for Molecular \& Cellular Biology, Osaka University, 1-3, Yamada-oka, Suita, Osaka 565, Japan (Tel: (81) 6-877-5244, Fax: (81) 6-875-2468)

\section{Radiation doses}

SIR-There are some serious faults in the paper by Gardner et al. ' claiming that four of the cases of child leukaemia out of 46 cases studied were due to radiation doses of $100 \mathrm{mSv}$ or more received over $6-10$ years by their fathers before the child was conceived, producing a heritable tendency to leukaemia.

No excess of leukaemias or of any other heritable diseases has been observed among 7,400 children of the irradiated survivors of Hiroshima and Nagasaki (5 leukaemias observed, 5.2 expected for an unirradiated but otherwise similar group). The natural background dose rates in Kerala in India and in parts of Brazil are close to the dose rate received at Sellafield by the fathers concerned, and no extra leukaemias have been reported among the offspring of male visitors to these areas.

Contrary to popular belief, hardly any of the recorded clusters of child leukaemias in Britain have any connection at all with ionizing radiation. The 165 child leukaemia deaths on Tyneside ${ }^{2}$ for example can be explained only as the effect of an infective agent, probably a virus; and at the other end of the scale the same applies to the three leukaemias that occurred in the United States in a single house between 1958 and $1965^{3}$.

The strongest reason for rejecting the Gardner hypothesis is that a far simpler explanation of child leukaemia clusters has been suggested by Kinlen ${ }^{4}$. He suggested that the frequent association of leukaemia with nuclear and other large establishments arose when a large influx of population from elsewhere, some of them carrying a virus to which they themselves were immune, was added to a small isolated community in which the children were not immune. Strong support was gained for his theory when he found that the small, excess-radiation-free and relatively isolated Scottish town of Glenrothes had had a rapid and large increase of population from elsewhere - and had then experienced a leukaemia epidemic among the children of the earlier inhabi- tants. This theory was widely accepted as an adequate reason for the Seascale leukaemias without any contribution from ionizing radiation.

\section{Vernon Road,}

J. H. FREMLIN

\section{Edgbaston,}

Birmingham B16 9SH, UK
1. Gardner, M.J. Brit. med. J. 300, 423-429 (1990)
2. The Listener 26 November 1987
3. Garfinkel, L. CA-A Cancer J. for Clinicians 37, No. 1, 20 (1987).
4. Kinlen, L. Lancet II, 1323-1327 \& 1506 (1989).

SIR - In the wake of the Gardner report (see Nature 343, 679; 1990), the British nuclear industry might usefully adopt the guidance given in the Control of Substances Hazardous to Health (COSHH, 1988) Regulations, which came into force on 1 October 1989.

Section 7 (1) of the COSHH Regulations states that "every employer shall ensure that the exposure of his employees to substances hazardous to health is either prevented or, where this is not reasonably practicable, adequately controlled". This should apply to both toxic and radioactively hazardous materials.

Furthermore, Section 12 (1) stipulates that "an employer who undertakes work which may expose his employees to substances hazardous to health should provide that employee with such information, instruction and training as is suitable and sufficient for him to know: (a) the risks to health created by such exposure; and (b) the precautions which should be taken".

Based on interviews with Sellafield workers broadcast and reported in the wake of the Gardner report, I judge that British Nuclear Fuels plc's health physics expertise has not on all occasions been shared fully with their workforce.

DAVID LOWRY

Casella,

Regent House,

Wolseley Road,

Kempston, Bedford MK42 7JY, UK

\section{Eminent engineers}

SIR-John Maddox, in 'Engineer in the White House' (Nature 344, 103; 1990), says that "Mr John Sununu, Chief of Staff at President George Bush's White House, is probably the first person with a technical background in such an influential position since Benjamin Franklin officiated at the court of George Washgton".

It is questionable whether Franklin 'officiated at the court of George Washington', but it is a fact that Presidents Herbert Hoover and Jimmy Carter were both engineers.

Institute of Geophysics and JOHN W. MILES

Planetary Physics,

University of California, San Diego, La Jolla, California 92093-0225, USA 